\title{
EPISTEMOLOGÍA Y VIOLENCIA. APROXIMACIÓN A UNA VISIÓN INTEGRAL SOBRE LA VIOLENCIA HACIA LAS MUJERES
}

CARMEN MAGALLÓN PORTOLÉS

Fundación Seminario de Investigación para la Paz, Zaragoza

\section{NORMALIDAD PATOLÓGICA, VISIBILIDAD Y EPISTEMOLOGÍA}

La raíz más perniciosa de toda violencia es aquella que está arraigada en supuestos que la convierten en invisible. Son supuestos que diluyen las manifestaciones de la violencia en el entramado de lo normalizado en una cultura. Esta normalidad conforma las mentalidades y las reproduce, haciendo visibles unos hechos e impidiendo ver otros. Una normalidad que invisibiliza la violencia no puede ser catalogada de sana sino de patológica. El apelativo de normal puede aplicarse por su amplitud estadística: el hacer de muchos construye norma; el de patológica lo merece si el resultado es la muerte o el maltrato cotidiano. Aunque es la denominación más acorde con la situación actual, normalidad patológica es un contrasentido, y lo es en su expresión profunda, porque una conducta patológica en la convivencia no puede formar parte de las condiciones de normalidad ${ }^{1}$.

La violencia hacia las mujeres ha sido, y sigue siendo en gran medida, un tipo de violencia que no era considerada como tal, invisible por tanto. La muerte de tantas mujeres a manos de su marido, amante o compañero; el maltrato, la descalificación, la cercenación de su libertad o de sus derechos, la subordinación de sus capacidades como ser humano y muchas otras restricciones, han sido parte de una normalidad que merece ser considerada patológica. En los últimos años, en este país, se están dando pasos para que el provocador título

1. Sobre esta normalidad véase LORENTE ACOSTA, Miguel: "Lo normal de lo anormal: raíces y frutos de la violencia contra las mujeres», en Fundación Seminario de Investigación para la Paz (ed.): Pacificar violencias cotidianas, Zaragoza, Departamento de Cultura, Gobierno de Aragón, 2003, pp. 169-192. Sobre normalidad patológica, MAGALLón PORTOLÉs, Carmen: «Compartir el cuidado, compartir la autoridad: hacia una cultura del respeto entre hombres y mujeres», en Fundación Seminario de Investigación para la Paz (ed.): Op.cit., pp. 243-272. 
de un libro, Mi marido me pega lo normal , no sólo deje de ser una frase pronunciable sino ni tan siquiera pensable.

Pese a lo arraigada que está la idea de que los hechos están ahí para ser percibidos, ya sea a simple vista, ya a través de aparatos diversos de medida, esto no sucede ni tan siquiera en las ciencias que tratan de comprender y explicar los fenómenos físicos, pues ya desde Hanson sabemos que la observación está cargada de teoría ${ }^{3}$. Un razonamiento ya clásico es partir de la noción kuhniana de paradigma ${ }^{4}$. Un paradigma o modelo es una visión del mundo que contiene elementos básicos de creencia de lo que es la realidad y que constituye un marco general que estructura la mirada, las observaciones, permitiendo ver unas cosas y no otras. Kuhn puso de manifiesto que las aportaciones verdaderamente revolucionarias en la ciencia fueron el resultado de un cambio de paradigma, de un cambio en las formas de ver la realidad. Al situarse en un nuevo paradigma, los científicos fueron capaces de ver nuevos hechos y nuevas relaciones entre ellos, que aunque estaban ahí no eran visibles desde el antiguo paradigma.

El paradigma que ha de cuestionarse para hacer visibles las dimensiones de la violencia contra las mujeres es aquel que legitima la desigual situación, la subordinación y la inexistencia simbólica de las mujeres.

El paradigma de subordinación fue puesto en cuestión por voces individuales en la historia, entre otras, por Mary Woollstonecraft en su Reivindicación de los derechos de la mujer ${ }^{5}$, por François Poulain de la Barre, cuando afirmó que la mente no tiene sexo ${ }^{6}$ o por Virginia Woolf cuando vislumbró y alentó la opción de las mujeres de desarrollar una práctica y un pensamiento propios ${ }^{7}$. También por otras pensadoras y pensadores que se situaron simbólicamente fuera del paradigma dominante.

El movimiento de mujeres ha ido paralelo a la emergencia de un saber sobre el mundo, de un conocer, que sólo ha sido posible cuando ellas se han constituido en sujetos del conocimiento. Epistemólogas feministas ${ }^{8}$ han puesto de manifiesto que el conocimiento que crece impulsado por un movimiento social, en este caso el feminismo, da como resultado un conocimiento menos sesgado que el supuestamente neutro. Han criticado la noción de sujeto universal, por no ser tal sino masculino; han mostrado que todo conocimiento es

2. LORENTE ACOSTA, Miguel: Mi marido me pega lo normal. Agresión a la mujer: realidades y mitos, Barcelona, Ares y Mares, 2001.

3. HAnson, N. R.: Patrones de descubrimiento. Observación y explicación, Madrid, Alianza, 1977.

4. KuHn, Thomas: La estructura de las Revoluciones Cientificas, México/Madrid, Fondo de Cultura Económica, 1981.

5. WoolistoneCraft, Mary: Vindicación de los derechos de la mujer, Madrid, Cátedra, edición de Isabel Burdiel, col. Feminismos, n 18, 1996.

6. Poulain De La BARRe, François: De L'Egalité des deux sexes. Discourse physique et moral ou l'on voit l'importance de se défaire des prejugés, 1673. (Trad. Sobre la igualtat dels dos sexes, Valencia, Univesitat de Valencia, Col-lecció Comunicació; sèrie Feminismes, 1, 1993).

7. Woolf, Virginia: Tres Guineas, Barcelona, Lumen, 1977.

8. Sandra HARDing, Nancy HARSTOCK y Donna HARAWAY entre otras. Una aproximación a sus planteamientos puede verse en MAGALLÓN PORTOLÉs, Carmen: Pioneras españolas en las ciencias, Madrid, CSIC, 2004, $2^{a}$ ed., pp. 36-61. 
situado y que nace de la experiencia de un sujeto colectivo. Partir de la vida de las mujeres, ha permitido establecer nuevos hechos, desvelar sesgos en las teorías dominantes y proporcionar visiones diferentes de la realidad social y física. Estas bases han permitido sacar a la luz realidades antes no percibidas: la violencia contra las mujeres ha dejado de ser invisible cuando éstas han peleado por hacerla visible.

Es importante destacar esta relación entre movimientos sociales y epistemología. La crítica de las bases sobre las que se apoya el conocimiento, la crítica epistemológica, ha surgido con fuerza desde los grupos sociales excluidos, aquellos que no han sido tomados en consideración por el saber instituido, cuya experiencia no ha contado en la historia. En el Foro Social Mundial (FSM) de Porto Alegre, espacio de encuentro, intercambio y coordinación de movimientos sociales e iniciativas a favor de la instauración de otro orden mundial, Boaventura de Sousa Santos ha dicho que las prácticas del FSM muestran otro tipo de realidad alternativa, en la que se hacen visibles sujetos y fenómenos que la dinámica social hegemónica produce como no existentes, y que no hay justicia social global sin justicia cognitiva global. El FSM, a su entender, da a luz y crece en una epistemología que ha llamado del Sur.

Movimiento social, feminismo, y validación de un saber nuevo, no recogido en la visión tradicional del conocimiento, se dan la mano. Lo que está en juego, en definitiva, es el debate sobre la realidad misma, y es esta pugna por la realidad, cuyos términos están abocados a ser objeto de negociación, la que convierte a la epistemología en una pieza clave.

Desde nuevas bases epistemológicas es posible salirse del orden simbólico predominante y confrontarse con la lógica que sustenta el orden de la violen$\mathrm{cia}^{10}$. En el caso de la violencia contra las mujeres, hay que perseguir y castigar a los culpables, y a la vez modificar la mentalidad social que sustenta el mantenimiento de esta violencia. Es esto último, sobre todo, lo que exige razonar con otra lógica, pensar desde otro marco, y promover nuevos modelos identitarios y de relación entre hombres y mujeres.

\section{LAS DIMENSIONES DE LA VIOLENCIA}

Para la elaboración de una teoría integral sobre la violencia contra las mujeres, podemos apoyarnos en las teorizaciones de Johan Galtung ${ }^{11}$ sobre la violencia. Este investigador sueco, pionero en los estudios sobre paz y conflictos, plantea un modelo triangular para esquematizar las relaciones entre los tres tipos de violencia (situados en los vértices) que engloban, a su entender, el

9. De Sousa SANTOS, Boaventura: O Fórum Social Mundial. Manual de uso, Sao Paulo, Cortez editora, 2005.

10. GRAU, Elena; IBÁÑEZ, Violeta y RIBERA, Isabel: «Hacer la paz: política y relaciones civilizadoras», en Fundación SIP (ed.): Propuestas para una agenda de paz, en prensa.

11. GALTUNG, Johan: Paz por medios pacíficos. Paz y conflicto, desarrollo y civilización (Trad. Teresa Toda), Bilbao, Bakeaz, 2003. 
conjunto de violencias: la violencia directa, la violencia estructural y la violencia cultural. Galtung conceptualiza la violencia como:

«afrentas evitables a las necesidades humanas básicas, y más globalmente contra la vida, que rebajan el nivel real de la satisfacción de las necesidades por debajo de lo que es potencialmente posible. Las amenazas de violencia son también violencia (...) Las cuatro clases de necesidades básicas -resultado de exhaustivos diálogos en muchas partes del mundo- son: necesidades de supervivencia (negación: muerte, mortalidad); necesidad de bienestar (negación: sufrimiento, falta de salud); identidad, necesidad de representación (negación: alienación); y necesidad de libertad (negación: represión)» ${ }^{12}$.

La existencia de una violencia directa contra las mujeres es bien patente ${ }^{13}$, se materializa en hechos que van en contra de las necesidades básicas, tal como las contempla este modelo: contra la necesidad de supervivencia, la muerte de tantas mujeres; contra la necesidad de bienestar, el maltrato, el desprecio, la descalificación, el acoso; contra la necesidad de una identidad, la alienación identitaria por imposición de un modelo estereotipado de mujer o por reducción al varón, y en cualquier caso con consideración de ciudadanía de segunda; y contra las necesidades de libertad, la negación de derechos y la disminución de opciones vitales. Si la violencia directa suele ser un acontecimiento eventual, para muchas mujeres es un hecho cotidiano, una forma de vida en la que están inmersas hasta que logran escapar de ella.

La violencia estructural es un proceso coyuntural, según Galtung, en cuyo centro se halla la explotación. En el caso de las mujeres la refleja mejor el concepto de dominación, algo que va más allá de lo económico. Se trata de una violencia derivada del lugar que ellas ocupan en el orden económico y de poder hegemónicos. El que la estructura de la propiedad y de los salarios sea desigual, cobrando menos las mujeres por trabajos iguales a los de los hombres, que la pobreza en el mundo tenga rostro de mujer -la feminización de la pobreza-, es violencia estructural contra ellas. También lo es el que el poder con mayúsculas, responsable de la toma de decisiones importantes que atañen a las vidas de hombres y mujeres, esté sesgado a favor de los hombres. Ellos son quienes ocupan los cargos importantes, las presidencias de los gobiernos, las jefaturas de las iglesias, los puestos dirigentes de la mayoría de las instituciones y corporaciones. También es violencia estructural, por lo que tiene de incremento de pobreza y de carga de trabajo añadida, el que la mayoría de las familias monoparentales, con hijos pequeños o mayores dependientes, caiga bajo la responsabilidad única de una mujer.

La división sexual del trabajo está también en la base de una violencia estructural. No sólo por la existencia de una doble jornada material sino por la

12. Ibíd., p. 262.

13. Hoy mismo, 4 de julio de 2005, mientras termino de escribir este artículo oigo en las noticias que una mujer más ha muerto a manos de su marido. Se trata de la víctima que hace el número 30 y el hecho ha sucedido en la ciudad en que vivo: Zaragoza. 
extracción de una plusvalía de carácter afectivo, que además no es reconocida. Retomo aquí al respecto lo publicado hace años en la revista En pie de paz:

"Ayer y hoy las mujeres han ofrecido su tiempo para que otros, ellos, se sientan bien. Han sido las escuchadoras, las sanadoras, las repartidoras de equilibrio, las cuidadoras por excelencia. De este modo ellos han podido realizarse profesionalmente: viajar, dar conferencias, trabajar en el campo o en la política de sol a sol, escribir libros, llegar a ser célebres, todo sin que les remuerda la conciencia o se cierna sobre ellos la mínima duda en torno a las posibles lagunas que pueda acarrear esta su dedicación en exclusiva, o incluso respecto a la legitimidad de su proceso de desarrollo personal (...) Es un tópico decir que detrás de un hombre importante siempre hay una mujer oscura que le apoya. No es tan tópico indagar los costes para las mujeres. Los varones les están extrayendo una plusvalía afectiva que les permite obtener una serie de ventajas de poder y autorrealización» ${ }^{14}$.

Finalmente, la violencia cultural es simbólica y persistente en el tiempo. Siempre según Galtung, anida "en la religión y la ideología, en el lenguaje y el arte, en la ciencia y en el derecho, en los medios de comunicación y en la educación» ${ }^{15}$. Su función es legitimar las otras violencias, la directa y la estructural. La violencia simbólica en contra de las mujeres se halla en la mayoría de las creencias religiosas en las que la deidad es masculina, en las ideas sobre la naturaleza de la mujer elaboradas por la filosofía y la ciencia, que la han situado en niveles más cercanos a los animales -la Naturaleza- que al ser humano racional ${ }^{16}$; en la literatura y el arte, en las que predominan las obras donde la mujer es objeto de la mirada, en vez de sujeto creativo y autónomo.

Lo importante del modelo triangular de Galtung es que facilita la comprensión de los flujos causales que se establecen entre los tres tipos de violencia. Estos flujos circulan en todas las direcciones, ya que la violencia se origina en cualquiera de los vértices, pero el principal es el que va de la violencia cultural a la violencia directa pasando por la estructural. La desvalorización simbólica de la mujer (violencia cultural) la abocó históricamente a un estatus de subordinación y exclusión institucional (violencia estructural), y esta marginación y carencia de poder favoreció su conversión en objeto de abuso físico (violencia directa).

\section{LA DESARTICULACIÓN DE LOS FLUJOS DE VIOLENCIA}

Eva Espinar ha investigado qué consecuencias de empobrecimiento (violencia estructural) están ligadas al maltrato (violencia directa). Utilizando un concepto de pobreza ligado al enfoque crítico de Amartya Sen y su revisión de la noción de necesidades humanas, concluye que además del empobrecimiento que supone el deterioro de salud física y psicológica que conlleva el maltrato,

14. MAGAllón PORTOLÉS, Carmen: «La plusvalía afectiva o la necesidad de que los varones cambien", En Pie de Paz, 17 (1991), Barcelona, p.10.

15. Galtung, Johan: Op. Cit., p. 20.

16. SCHIEBINGER, Londa: Nature's Body. Gender in the Making of Modern Science, Boston, Beacon Press, 1993. 
las mujeres maltratadas sufren un empobrecimiento material tanto durante la relación, en la que apenas son dueñas de nada, como después. El empobrecimiento se agrava con la ruptura, ya que entonces «la mujer prácticamente ha de empezar desde cero: cambio de residencia, asunción de las cargas familiares, mal estado de salud, paro, etc. ${ }^{17}$. Esta situación de desamparo ha llevado a muchas mujeres a sobrellevar en silencio el peso del maltrato.

En España está reciente la aprobación de una Ley integral contra la violencia de género ${ }^{18}$, que contempla una serie de medidas encaminadas fundamentalmente a proteger a las víctimas y castigar a los culpables. Es sin duda un paso importante en el camino de la eliminación de la violencia de género directa. No obstante, si damos crédito al modelo de flujos de violencia antes mencionado, habremos de concluir que no basta con actuar sobre la violencia directa y estructural, ya que estas violencias volverán a reproducirse si no se elimina la violencia cultural de carácter simbólico.

En el día a día, estamos comprobando cómo pese a que la igualdad de hombres y mujeres ante la ley es en nuestra sociedad cercana un hecho y un derecho inalienable, el reconocimiento formal no lleva consigo su puesta en práctica real. Vemos que el enunciado de leyes de igualdad entre los sexos, siendo un paso fundamental y necesario, no es suficiente. Las leyes son necesarias para regular la convivencia y también actúan sobre las conductas pero, en un momento histórico dado, no son sólo las leyes las que acotan la acción humana. El peso del pasado es demasiado poderoso como para ser eliminado de un día para otro. En particular, el lugar simbólico de la mujer y el hombre echa raíces en capas profundas de la cultura que nos conforma y que han sido y siguen siendo alimentadas por las creencias, la literatura, el arte, la filosofía, la ciencia, los relatos históricos, las costumbres y tradiciones. Al tratarse de comportamientos y modelos arraigados en la mentalidad, su desvelamiento y superación necesita un debate social y cultural más amplio y profundo.

La desigualdad se plasma también en cómo se conciben y estructuran las instituciones, construidas y definidas a la medida del varón arquetípico antes mencionado. Podemos preguntarnos por el lugar real que ocupa el legado de las mujeres en la esfera pública, incluyendo los propios hábitos de ser y de razonar de los hombres del siglo XXI, preguntarnos si la presencia femenina se ha hecho significativa, es decir existente, en la esfera pública.

El hombre que maltrata trata de dominar y doblegar a la mujer, controlando su vida y su voluntad, hasta llegar al extremo de eliminarla físicamente cuando no consigue lo que se propone. Este ejercicio cotidiano de poder está mostrando una mentalidad discriminatoria que da pie a una relación viciada: el varón que maltrata no reconoce en la mujer a un ser humano igual.

17. ESPINAR, Eva: "Conclusiones» de su tesis Violencia de género y procesos de empobrecimiento, dirigida por José María Tortosa Blanco y leída en la Universidad de Alicante en julio de 2003.

18. Ley Orgánica 1/2004, de 28 de diciembre, de Medidas de Protección Integral contra la Violencia de Género, BOE, n³13, 29 de diciembre 2004, pp. 42166- 42197. 
Epistemología y violencia. Aproximación a una visión integral sobre la violencia...

Por eso, pese a lo que pudiera parecer, hacer hincapié en la igualdad es una tarea que todavía nos concierne. Y sobre la que hay que seguir debatiendo pues no existe un acuerdo generalizado acerca de lo que esta igualdad ha de significar en la práctica. Es preocupante que los materiales para construir esa igualdad provengan fundamentalmente de los viejos esquemas masculinos, basados en la tradición del hombre blanco, occidental y de clase media. Ese concepto de igualdad sigue dejando en la invisibilidad la diversidad y la autoridad de la experiencia femenina histórica, y se muestra incapaz de eliminar la desconsideración social hacia las mujeres, embebida en las capas más hondas de la cultura.

¿Cómo puede erradicarse el desprecio por las mujeres si no se concede valor social a lo que han hecho en el pasado y a lo que hacen en el presente? Siempre he pensado que sacar a la luz los logros y experiencia de las mujeres, por ejemplo sus aportaciones a la ciencia ${ }^{19}$, contribuye a la construcción de una cultura de paz; que la emergencia social de la sabiduría de las mujeres, menos conocida y reconocida que la de los varones, puede colaborar a un cambio, aportando significados nuevos a la cultura y proporcionando raíces para una igualdad más profunda, capaz de ayudar a la erradicación de la violencia de género. Si queremos una verdadera igualdad entre hombres y mujeres, habrá que poner en plano de igualdad la experiencia histórica de ambos sexos y utilizar de algún modo los ladrillos -la experiencia- que ellas acumularon a lo largo de la historia, para la construcción del legado universal del conjunto humano.

En la insistencia por alcanzar una auténtica igualdad quisiera añadir un matiz, y es que ésta no puede darse, sin un reconocimiento de autoridad recíproco. La igualdad a que hago referencia supone el reconocimiento de la mujer como miembro de la comunidad, de pleno derecho, con todo lo que eso significa, incluida su diferencia. Esto tiene que ver con la puesta en cuestión de que el varón sea la medida de la igualdad, la norma. Una norma que emana de una sola parte, en este caso de uno de los sexos, siendo parcial se totaliza y, de este modo, anula a la otra parte. La norma común ha de construirse desde la doble experiencia y ha de modificar a ambos sexos. No hay reconocimiento de autoridad si no se hace visible la diversidad y los logros históricos de las mujeres en los lugares culturales donde éstos se dieron. En el cuidado de los demás, sí, pero también en la ciencia, en el pensamiento, en el arte, en todo resquicio de la cultura convivida. Aunque las mujeres se hayan abierto paso en las profesiones, en las instituciones, en la medida en que su presencia no modifique la norma de igualdad, modificando también al varón, seguirán sin tener un lugar de referencia simbólica.

El recorrido civilizatorio de las mujeres, con sus contribuciones a los campos específicos de la cultura y -a la vez- el trabajo de sostenimiento de la vida como central, aportan aspectos sustanciales para una noción de humanidad más evolucionada y civilizada. Es este modelo de compatibilización el que cobra importancia para una cultura de paz, una cultura en la que la vida humana, y

19. MAGALlÓn PORTOLÉS, Carmen: Pioneras españolas en las ciencias..., op. cit. 
no los intereses económicos; el cuidado del otro -y no la agresión y la dominación- estén en el centro.

Para este cambio no podemos quedarnos con una visión victimista. La imagen de las mujeres como víctimas es paralizante y no hace justicia a la diversidad, riqueza, empuje y protagonismo de los grupos de mujeres que tratan de mejorar el mundo en el que vivimos. Las mujeres hace tiempo que sin negar a las víctimas, nos hemos situado más allá del paradigma de la víctima. Incluso en el maltrato, las mujeres no sólo son víctimas. Ellas son las protagonistas de la supervivencia en muchas partes del planeta: defendiendo la calidad de la educación, o de los alimentos, los servicios en los barrios, la capa de ozono o el mantenimiento de los bosques. Esta sabiduría para la supervivencia es la que se ha expresado también en otros campos de la cultura, a lo largo de la historia. Y es la que ha de ponerse en circulación social para contribuir a una socialización diferente de ambos sexos.

\section{LA CUESTIÓN DE LA IDENTIDAD}

Un aspecto clave de la violencia simbólica, que sufren hombres y mujeres tiene que ver con la identidad. La cuestión de la identidad, en esta sociedad global que tiende a la homogeneización y el desarraigo, ha pasado a convertirse en uno de los núcleos duros de la conflictividad. La identidad responde a una necesidad muy potente de pertenencia, como seres sociales que somos; se construye pareciéndonos a unos y diferenciándonos de otros, enfatiza las similaridades dentro del grupo y las diferencias con los demás, por lo que lleva en sí una potencialidad de cierre y confrontación. En el caso de los sexos, la literatura especializada habla de una mayor obsesión y dificultad en el logro de una identidad masculina que en el de una identidad femenina. La confusión de los sexos, la indiferenciación sexual pesa como una amenaza sobre el sentimiento de identidad de ambos, aunque etnólogos y psicoanalistas coinciden en afirmar que esta fuente de angustia pesa más en el niño que en la niña, que los varones han de luchar más duramente que las mujeres para diferenciarse del otro y adquirir psicológicamente su sentimiento de identidad sexual ${ }^{20}$.

Como un legado histórico de las relaciones de dominación establecidas entre los sexos, la violencia identitaria que sufren hombres y mujeres es de doble cara porque se expresa tanto en la asignación de una identidad regida por esquemas estereotipados que constriñen la libertad y opciones vitales de ambos, como negando toda referencia identitaria. Ésta última negación afecta a las mujeres de un modo específico ya que la tendencia actual en los países occidentales es a reducir su identidad a la del hombre.

20. BADINTER, Elisabeth: L'un est l'autre, Paris, Odile Jacob, 1986. Traducción : El uno es el otro. Una tesis revolucionaria, Barcelona, Planeta,1987. 
Epistemología y violencia. Aproximación a una visión integral sobre la violencia...

\subsection{Identidades masculinas}

Myriam Miedzian ${ }^{21}$ mantiene que hombres y mujeres siguen anclados en papeles sociales estereotipados que se refuerzan entre sí y desde los que se construye la identificación entre masculinidad y violencia: son los niños quienes desde la infancia soportan una mayor presión social hacia una masculinidad expresada a través de conductas agresivas. Finalmente, todos, hombres y mujeres, somos víctimas de unos arquetipos potencialmente destructivos, pero son los valores entronizados por una mística masculina los que juegan un papel nuclear en la eclosión de la violencia criminal y de género, sin olvidar que son estos valores los que configuran la forma de pensar y decidir de la mayoría de los líderes políticos. Miedzian señala como principales valores de esta masculinidad hegemónica que se mantiene insidiosamente: la dureza y la represión de los sentimientos (no llorar, no tener miedo...), el afán de dominio, la represión de la empatía, y esa competitividad extrema que condiciona a los hombres a valorar por encima de todo la victoria y la gloria, y a encerrarse en las dicotomías nosotros/ellos o ganar/perder. De ahí es fácil la deriva hacia el ejercicio de la violencia contra las mujeres, pues alguien que cree

"que los hombres son por naturaleza dominantes y las mujeres sumisas, no sólo se sentirá profundamente herido si su esposa o novia le deja o si ella no se somete a sus deseos, sino que también experimentará su conducta (libre) como una ofensa humillante a su virilidad» ${ }^{22}$.

El modelo de varón con el que, en última instancia, se sigue midiendo un hombre en momentos duros de su vida, el modelo que en momentos de crisis parece regir, es un arquetipo en el que la dureza, el éxito, el ocultamiento de los sentimientos y el ejercicio de la dominación, forman parte del núcleo duro de su identidad. Es aquel que niega en sí cualquier rasgo femenino; en el que se da la ausencia de capacidades empáticas, de ponerse en el lugar del otro. Se trata de un arquetipo que hace sentirse profundamente herido al hombre ante una mujer que ejerciendo su libertad le dice no o, se marcha de su lado. Es este modelo el que todavía sigue siendo sutil o brutalmente hegemónico, en la socialización de los niños. Aunque existe una evolución de este arquetipo que deviene en diversidad en muchas capas de la población, todavía ellos desde la infancia, tienen que soportar una variedad de presiones sociales, que les empujan a construir y demostrar su masculinidad a través de conductas agresivas adecuadas al modelo.

Si la identidad del hombre crece desde una posición de dominación sobre la mujer, de modo que las conductas de afirmación de la mujer como ser libre pueden ser vividas por éste como una amenaza a su identidad y provocar una conducta violenta, puede decirse $-\mathrm{y}$ es una hipótesis con mucho apoyo

21. Miedzian, Myriam: Chicos son, hombres serán. Cómo romper los lazos entre masculinidad y violencia, Madrid, Horas y horas, 1995.

22. Ibid., p. 139. 
empírico- que la violencia contra las mujeres es el resultado de una guerra de identidad que libran los hombres consigo mismos.

De ahí el destacar la importancia que posee, para la eliminación de las raíces profundas de la violencia contra las mujeres, la persistencia en la reflexión y el rechazo social de los aspectos más nefastos de ese estereotipo masculino, aquellos que atan a los varones a los comportamientos violentos, en nombre de su rol. Luis Bonino ${ }^{23}$ habla de que el rol masculino produce molestares y malestares, es decir, hace sufrir a otros pero también a uno mismo. Muchos varones padecen problemas personales, emocionales y de relación: aislamiento, depresiones, obsesiones por no dar la talla, desencuentros con las mujeres, adicciones, dificultades sexuales, etc. El sufrimiento es más visible en niños y adolescentes. Las exigencias tan elevadas que exige el estereotipo se presentan como algo difícil de cumplir, pero a la vez su transgresión es causa de angustia, al ser interpretado como ambigüedad de si se es o no un hombre.

A la vez que se rechaza el viejo modelo, es preciso ofrecer nuevos modelos de identificación para el varón, para favorecer el cambio de los hombres. Esos modelos ya existen, porque el mundo es grande y diverso, pero todavía no han desplazado al varón dominante de su puesto hegemónico. Hoy, lo estamos viviendo, muchos hombres de nuestro entorno son sensibles, empáticos, cuidadores y no especialmente agresivos; pero el modelo al que dan vida tiene una menor visibilidad y hegemonía social (en la toma de decisiones políticas, en el cine, en la TV, en las novelas), de modo que nuestros adolescentes siguen alimentándose con los grandes mitos de la fuerza y la dominación masculina. Los nuevos modelos han de hacerse visibles y significativos, para que trasciendan culturalmente.

\subsection{Identidades femeninas}

La violencia simbólica sobre las mujeres se ejerce negando sentido y significado a su existencia y aportaciones. En este caso, los conceptos claves son invisibilidad y desvalorización. Invisibilidad como sujeto colectivo y desvalorización como negación de la importancia, para toda la humanidad, de lo realizado por las mujeres a lo largo de los siglos, sobre todo del trabajo de cuidado necesario para el mantenimiento y la reproducción de la vida humana ${ }^{24}$.

La tendencia a negar la diferencia entre los sexos para evitar que sea convertida en desigualdad, como ha sucedido en la corriente mayoritaria del pen-

23. BONINO, Luis: «Varones, género y salud mental: deconstruyendo la «normalidad» masculina», en Marta Segarra y Angels Carabi (eds.): Nuevas masculinidades, Barcelona, Icaria, 2000.

24. Teniendo en cuenta la experiencia de las mujeres, Anna Bosch, Cristina Carrasco y Elena Grau han conceptualizado el trabajo en sentido amplio como «la práctica de creación y recreación de la vida y de las relaciones humanas» («Verde que te quiero violeta. Encuentros y desencuentros entre feminismo y ecologismo", en Enric Tello: La historia cuenta. Del crecimiento económico al desarrollo humano sostenible, Barcelona, El Viejo Topo, 2005, p. 331), tomando las palabras de VVAA: "De dos en dos: las prácticas de creación y recreación de la vida y la convivencia humana", Cuadernos inacabados, 38 (2000), Madrid, Horas y horas. 
samiento occidental, ha generado este tipo de violencia simbólica. Pero el nudo problemático de la diferencia sexual no se desenreda negándola sino dilucidando en qué es relevante.

Historiadoras de la ciencia ${ }^{25}$ han puesto de manifiesto la importancia que tiene, para algo tan concreto como la salud, el tener en cuenta la diferencia sexual, y han establecido que el programa de investigación en medicina que toma en consideración la diferencia sexual y no es androcéntrico tiene superior capacidad de generar progreso científico que el programa alternativo y convencional de la neutralidad sexual, porque:

«1) resuelve un problema simbólico (rechazo a las desigualdades y/o subordinación entre los sexos); 2) es un programa aplicable en un campo de investigación muy extenso, como es toda la patología médica; 3 ) es aplicable en todos los niveles asistenciales y por todos sus actores o agentes sanitarios; 4) los resultados negativos son tan valiosos como los positivos, dado que la demostración de la ausencia de diferencias sexuales significativas o de sesgos de género del saber y praxis médica interesa desde el mismo momento de la sospecha de su existencia» ${ }^{26}$.

\section{VIOLENCIA SIMBÓLICA, EXISTENCIA E IDENTIDAD LIBRE}

La violencia simbólica contra las mujeres está encerrada en esta pinza entre identidad designada por otros - por la tradición sexista- y negación de toda identidad femenina. Por mi parte, no creo en universos identitarios cerrados. La mera idea me parece un peligro. Pero sí en la necesidad de una comunidad de referencia que de sentido a la experiencia propia, en este caso a la experiencia de las mujeres. Ahí están las reflexiones de Hannah Arendt, cuando dice que la falta de comunidad de pertenencia deja a un ser humano huérfano, sin lugar en el mundo, y que esta carencia ha sido causa de negación de derechos.

"Los refugiados, los apátridas, los encerrados en los campos de exterminio... han podido comprobar que la abstracta desnudez de ser nada más que humanos era su mayor peligro (...). Parece como si un hombre que no fuera más que un hombre hubiera perdido las verdaderas cualidades que hacen posible a otras personas tratarle como a un semejante (...) la privación fundamental en el terreno de los derechos no es la de la libertad, sino la de 'un lugar en el mundo que haga significativas las opiniones y efectivas las acciones' esto es, la privación de una comunidad de pertenencia, de una nación soberana en la que poder vivir como ciudadano el derecho a la diferencia frente a los otros pueblos $\aleph^{27}$.

25. Véanse los trabajos del grupo Genciana, formado por Consuelo Miqueo, María José Barral, Isabel Delgado, Teresa Fernández y Carmen Magallón. Entre otros: M.J. BARRAL; C. MAGALLón; C. MiqueO y D. SÁNCHEZ (eds.): Interacciones ciencia y género: discursos y prácticas científicas de mujeres, Barcelona, Icaria-Antrazyt, 1999 y MioueO, C.; BARRAL, Mª J.; FERnÁndeZ-TuRRADO, T.; MAGALlón, C. (Grupo Genciana): "Del análisis crítico a la autoridad femenina en la ciencia», Feminismo/s, 1 (2003), Universidad de Alicante, pp. 195-215.

26. Miqueo, Consuelo: "Genealogía de los sesgos de género en la ciencia y práctica médica contemporánea», en J. Martínez Pérez et. al. (coord.): La medicina ante el nuevo milenio: una perspectiva histórica, Cuenca, Universidad de Castilla la Mancha, 2004, pp. 45-66.

27. ARENDT, Hannah: Los orígenes del totalitarismo: Imperialismo, Madrid, Alianza, 1987, p. 435. 
Arendt se refiere a una comunidad política, pero su razonamiento es aplicable a las mujeres como sujeto colectivo en el interior de una determinada comunidad política: la falta de una comunidad de referencia, de una voz como sujeto colectivo condujo durante siglos a una situación de falta de derechos que aún se arrastra hoy.

Ahora bien, el derecho a una referencia de grupo, la reivindicación de un significado para el hecho de ser mujer en la sociedad, ¿equivale a la búsqueda de una identidad esencial, a modo de lecho de roca escondido en algún estrato reprimido de nuestro ser?

En la búsqueda de respuesta a esta y otras cuestiones similares es donde veo interesante el planteamiento de Chantal Mouffe. Esta autora niega la existencia de identidades esencialistas o naturales; aplica a las mujeres la idea de que es el exterior, múltiple y contradictorio el que nos constituye; en cualquier instante, seríamos el resultado precario de un mestizaje, de un entrecruzamiento de posiciones de sujeto ${ }^{28}$ con las que podemos identificarnos, un resultado que es a su vez inestable. La identidad de las mujeres, como cualquier otra, es para ella una identidad nómada sujeta a lo contingente.

"En la medida en que toda objetividad depende de una alteridad ausente, necesariamente se remite a esa alteridad, está contaminada por ella. Esto impide para siempre la seguridad de una identidad que pertenezca a uno y a la que uno pertenezca (...) De hecho la identidad se constituye a partir de una multiplicidad de interacciones y esto no ocurre dentro de un espacio cuyos contornos podrían ser delimitados. Muchas investigaciones feministas o inspiradas por la corriente 'postcolonial' han mostrado que se trata siempre de un proceso de 'sobredeterminación' que teje vínculos muy complejos entre muchas formas de identificación y una red compleja de diferencias. Para pensar en la identidad, hay que tener en cuenta a la vez la multiplicidad de los discursos y de las relaciones de poder que la atraviesan y el carácter complejo de complicidad y de resistencia que proporcionan la trama de las prácticas en las que queda implicada esa identidad. En lugar de ver las distintas formas de identidad y de pertenencia como una perspectiva y una experiencia, hay que reconocer allí lo que se juega siempre como una relación de fuerzas ${ }^{29}$.

Ese exterior constituyente es un juego de tensiones que actúa como un campo de fuerzas, y es sobre esas fuerzas, sobre los discursos sociales, sobre los que se puede incidir. Las mujeres crecieron políticamente como voz precisamente en la rebelión ante ese exterior que las constituye en la sumisión y la inferioridad. Puede decirse que, entre las feministas, hay un acuerdo amplio de rechazo de una identidad impuesta. Al mismo tiempo, sabiendo el peso de lo simbólico, algunas piensan que situarse sólo en el filo desubicador de la negación actúa en la práctica como una estrategia de disolución. La conclusión es

28. Para una discusión más amplia sobre el pensamiento de Chantal Mouffe véase: MAGALLóN PORTOLÉs, Carmen: «Identidad y conflicto desde el pensamiento de Chantal Mouffe», Riff-Raff. Revista de Pensamiento y Cultura, 27 (2005), 2a época, pp. 179-199.

29. Mouffe, Chantal: «Por una política de la identidad nómada», Debate feminista, 7-14 (1996), p. 9. 
que la reafirmación y la negación de 'las mujeres' es un conflicto vivo. A este respecto, la imagen de un campo de fuerzas usada por Mouffe es muy gráfica y cuadra con las tensiones que rodean este debate. En este caso, y en otros, se constata que "la existencia social de un grupo se construye siempre en el conflicto (...) 'la identidad cultural' es el escenario y también el objeto de combates políticos $\aleph^{30}$.

Un ejemplo de esta tensión identitaria múltiple es el que relata Pragna Patel del colectivo South Black Sisters (SBS) ${ }^{31}$.

A lo largo de nuestros veinte años de existencia, hemos intentado sacudirnos las identidades encajadas sobre nosotras por parte de la comunidad, el movimiento anti-racista y por el Estado. Los elementos reaccionarios dentro de nuestra comunidad buscan imponernos una identidad que nos confine en los roles tradicionales de esposas y madres, con el fin de asegurar que los valores religiosos y culturales permanecen intactos y son transmitidos de una generación a otra. Hemos tenido que resistirnos también a los intentos realizados por los movimientos anti-racistas más progresistas de adscribir sobre nosotras una identidad negra, en singular. Tales construcciones, algunas veces abiertamente y más a menudo tácitamente, demandan la subyugación de todas las demás identidades en aras de la justicia racial. Esto ha conducido a la negación de otras experiencias e identidades, como las que emergen del género, la casta, la clase y otras divisiones dentro de nuestras comunidades. Añadido a esto, nos hemos encontrado teniendo que resistir a las categorías y estereotipos racistas promovidos por el Estado Británico, cuyo efecto ha sido subordinar la diferencia, denigrar las culturas y religiones minoritarias, y confinarnos en el estatus de ciudadanas de segunda clase (o, en el caso de refugiadas, de tercera) ${ }^{32}$.

Se trata de un ejemplo que muestra las tensiones identitarias que se cruzan en este grupo de mujeres. Ellas rechazan la manipulación de los rasgos identitarios impuestos y ponen en cuestión la reducción de su identidad a un conjunto de características cerradas que niegue su apertura a otras referencias.

En esta tensión, el planteamiento de Mouffe, que aquí no puede ser desarrollado por falta de espacio ${ }^{33}$, no niega la posibilidad de lograr la unidad de las mujeres ya que las distintas posiciones de sujeto pueden ser articuladas. La negación de un vínculo a priori no tiene por qué transformarse en una separación efectiva. De hecho, no pueden negarse los constantes esfuerzos hechos por las mujeres y tantos otros grupos para establecer vínculos históricos, cuyo resultado fue la aparición del feminismo, en todas sus vertientes.

30. Ibíd., p. 10.

31. Se trata de un colectivo de mujeres del Sur de Asia, radicado en Southall, Londres, área cosmopolita con predominio de población asiática, en la que están presentes todos los grupos étnicos y religiosos del Subcontinente Indio. El fragmento es de PATEL, Pragna: "Difficult Alliances: Treading the Minefield of Identity and Solidarity", Soundings, 12 (Summer 1999), pp. 115-129 (mi traducción del inglés). Doy las gracias a Cynthia Cockburn, de Mujeres de Negro de Londres, por enviarme una copia y dármelo a conocer.

32. PATEL, Pragna: Op. cit., p. 2.

33. Puede verse en Mouffe, Chantal: El retorno de lo político. Comunidad, ciudadanía, pluralismo, democracia radical, Barcelona, Paidós, 1993. Y ciertos desacuerdos en MAGALLón PORTOLÉS, Carmen: "Identidad y conflicto desde el pensamiento de Chantal Mouffe», op. cit. 
En cualquier caso, abierto el horizonte del conflicto identitario e identificados los nudos que convierten el conflicto en violencia, directa y simbólica, queda un desasosiego sobre cómo poner en positivo lo que cada uno y cada una somos o queremos ser. Como escribieron Anna Bosch y Elena Grau, hemos de continuar indagando el significado de ser diferentes, de que haya dos sexos en el mundo, pues hasta ahora nos hemos limitado, en el mejor de los casos, a pensar en un neutro abarcador -que esconde a uno de los sexos- y en el peor a una definición impuesta y forzada sobre el otro -el eterno femenino, que eterniza la subordinación-. Dos sexos y un mundo en el que la tarea civilizatoria de las mujeres no se ha hecho visible, no se ha hecho mundo común ${ }^{34}$.

Junto a Elena Grau y el grupo Giulia Adinolfi ${ }^{35}$, que lo hacen objeto de reflexión constante, muestro mi empeño en encontrar un sentido al ser mujer y rechazo considerarlo algo irrelevante ${ }^{36}$. Grau ha rescatado los escritos de Giulia Adinolfi ${ }^{37}$, profesora, intelectual, militante del PSUC y fundadora de la revista Mientras Tanto, que hace más de veinticinco años escribió:

"Las mujeres tendrían que ser capaces de asumir crítica y libremente su propia tradición, de medirse con ella, de rechazar sus elementos negativos y de reivindicar, en cambio, aquellos otros que -cualquiera que haya sido su función- revelan hoy una potencialidad positiva ${ }^{38}$.

Todavía estamos en ello.

\section{BIBLIOGRAFÍA}

BADINTER, Elisabeth: L'un est l'autre, Paris, Odile Jacob, 1986.

- XY. La identidad masculina, Madrid, Alianza, 1993.

BONINO, Luis: "Varones, género y salud mental: deconstruyendo la "normalidad» masculina", en Marta Segarra y Angels Carabi (eds.): Nuevas masculinidades, Barcelona, Icaria, 2000.

Bosch, Anna; CARrasco, Cristina y GraU, Elena: "Verde que te quiero violeta. Encuentros y desencuentros entre feminismo y ecologismo", en Enric Tello: La historia cuenta. Del crecimiento económico al desarrollo humano sostenible, Barcelona, El Viejo Topo, 2005, pp. 321-346.

Bosch, Anna y GraU, Elena: "Construyendo un mundo común. La tarea civilizatoria de las mujeres", En Pie de Paz, 45 (1997), pp. 45-48.

Galtung, Johan: Paz por medios pacíficos. Paz y conflicto, desarrollo y civilización (Trad. Teresa Toda), Bilbao, Bakeaz, 2003.

34. Bosch, Anna y GRAU, Elena: «Construyendo un mundo común. La tarea civilizatoria de las mujeres", En Pie de Paz, 45 (1997), pp. 45-48.

35. Formado por Elena Grau, Violeta Ibáñez e Isabel Ribera, de Barcelona.

36. Grau BiosCA, Elena: «1980-2005, veinticinco años sin Giulia y con Giulia», Mientras Tanto, 94 (Primavera 2005), pp. 39-44, p. 39.

37. Sobre Giulia Adinolfi, véase el número 94 (Primavera 2005) de la revista Mientras Tanto, que está dedicado a su memoria.

38. ADINOLfi, Giulia: «Sobre las contradicciones del feminismo», Mientras Tanto, 94 (Primavera 2005), pp. 83-85, p. 85. Citado por Elena Grau en Op. Cit., p. 41. 
Epistemología y violencia. Aproximación a una visión integral sobre la violencia...

GiUlia AdinOlfi, GRUPO: "Construirnos como sujeto, constituirnos en medida del mundo", Mientras Tanto, 48 (1992), pp. 19-32.

GRAU BiosCA, Elena: «Pensar la política desde la diferencia femenina», en Joan Antón Mellón (ed.): Ideologías y movimientos políticos contemporáneos, Madrid, Tecnos, 1998.

Grau BioscA, Elena: «1980-2005, veinticinco años sin Giulia y con Giulia», Mientras Tanto, 94 (Primavera 2005), pp. 39-44.

De Sousa SANTOS, Boaventura: O Fórum Social Mundia. Manual de uso, Sao Paulo, Cortez editora, 2005.

ESPINAR, Eva: «La violencia doméstica como factor de empobrecimiento», en José $M^{a}$ Tortosa (coord.): Mujeres pobres, indicadores de empobrecimiento en la España de hoy, Madrid, Cáritas Española, 2002, pp. 101-125.

- Violencia de género y procesos de empobrecimiento, tesis dirigida por José María Tortosa Blanco y leída en la Universidad de Alicante en julio de 2003.

Hanson, N. R.: Patrones de descubrimiento. Observación y explicación, Madrid, Alianza, 1977.

LOREnTE ACOSTA, Miguel: Mi marido me pega lo normal. Agresión a la mujer: realidades y mitos, Barcelona, Ares y Mares, 2001.

- "Lo normal de lo anormal: raíces y frutos de la violencia contra las mujeres», en Fundación Seminario de Investigación para la Paz (ed.): Pacificar violencias cotidianas, Zaragoza, Departamento de Cultura, Gobierno de Aragón, 2003, pp.169-192.

MAGALLÓN PORTOLÉS, Carmen: «La plusvalía afectiva o la necesidad de que los varones cambien", En Pie de Paz, 17 (1991), Barcelona, p. 10.

- "Compartir el cuidado, compartir la autoridad: hacia una cultura del respeto entre hombres y mujeres», en Fundación Seminario de Investigación para la Paz (ed.): Pacificar violencias cotidianas, Zaragoza, Departamento de Cultura, Gobierno de Aragón, 2003, pp. 243-272.

- Pioneras españolas en las ciencias, Madrid, CSIC, $2^{\text {a }}$ ed., 2004.

- "Identidad y conflicto desde el pensamiento de Chantal Mouffe», Riff-Raff. Revista de

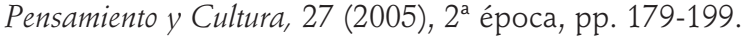

MiEDZIAN, Myriam: Chicos son, hombres serán. Cómo romper los lazos entre masculinidad y violencia, Madrid, Horas y horas, 1995.

MiqueO, Consuelo: "Genealogía de los sesgos de género en la ciencia y práctica médica contemporánea», en J. Martínez Pérez et. al. (coord.): La medicina ante el nuevo milenio: una perspectiva histórica, Cuenca, Universidad de Castilla la Mancha, 2004, pp. 45-66.

Miqueo, C.; Barral, Ma J.; Fernández-Turrado, T.; Magallón, C. (Grupo Genciana): "Del análisis crítico a la autoridad femenina en la ciencia», Feminismo/s, 1 (2003), Universidad de Alicante, pp. 195-215.

MoufFe, Chantal: "Por una política de la identidad nómada», Debate feminista, 7-14 (1996), p. 9.

POUlAin De LA BARRE, François: De L'Egalité des deux sexes, Discourse physique et moral our l'on voit l'importance de se défaire des prejugés, 1673. Traducción: Sobre la igualtat dels dos Sexes, Valencia, Universidad de Valencia, 1993.

SCHIEBINGER, Londa: Nature's Body. Gender in the Making of Modern Science, Boston, Beacon Press, 1993.

Sousa Santos, Boaventura de: O Fórum Social Mundial: Manual de uso, Sao Paulo, Cortez editora, 2005.

VVAA: «De dos en dos: las prácticas de creación y recreación de la vida y la convivencia humana», Cuadernos inacabados, 38 (2000), Madrid, Horas y horas.

Woolf, Virginia: Tres Guineas, Barcelona, Lumen, 1977. 